\title{
CO-TEACHING APPROACHES: HEARING IMPAIRED STUDENTS IN MAINSTREAM CLASS
}

\author{
Aliza Alias $^{1 *}$, Umithayyibah Ramly ${ }^{2}$ \\ ${ }^{1}$ Dr., Universiti Kebangsaan Malaysia, MALAYSIA, email eliza@ukm.edu.my \\ ${ }^{2}$ Ms., Alor Akar Secondary School, Pahang, MALAYSIA, email umithayyibah@gmail.com \\ ${ }^{*}$ Corresponding author
}

\begin{abstract}
Co-teaching approaches emphasize on the collaboration and communication between members of a teaching team to meet the learning objectives and learning needs of all students in a classroom. Co-teaching is typically perceived as two educational professionals working together to teach a group of heterogeneous learners including those with special needs. This study identifies the co-teaching approaches that were implemented by the teachers in mainstream classes that were attended by hearing impaired students. Participants in this case study were special education teachers who were involved in inclusive education for hearing impaired students in a secondary school. These teachers collaborated with general education teachers to teach subjects such as Geography, Mathematics and Science in mainstream classes that have hearing impaired students. Three special education teachers who specialized in teaching hearing impaired students were interviewed. The interview findings were transcribed and analyzed based on themes that emerged which are the co-teaching approaches chosen, benefits of co-teaching approaches, successful of co-teaching and challenges that faced by the teachers in implementing the co-teaching approaches in the mainstream classes. This study found that special education teachers preferred to use two co-teaching approaches which are parallel teaching that teach two groups in a class simultaneously; and one teach-one assists approach that is when the general education teacher teaches, the special education teacher assists in the teaching process. Most of the time, the special education teachers' roles also include as interpreters in the class. The teachers were not only signing to the hearing impaired students what the mainstream teachers were talking or teaching in class but also teaching or assisting the students to understand the lesson taught in the class. The special education teachers also interpreted the questions, answers or opinions from hearing impaired student to the teacher or to the classmates during the lesson. Thus, the interpreters' role in the classroom included translating teacher speech, voicing student sign language, mediating communication between deaf students and their peers, and monitoring overall classroom behavior. The approaches of co-teaching motivated hearing impaired students to build social connection or interaction with hearing classmates. The factors that contributed to co-teaching success were the planning and preparation done together with general education teachers, supports from administrators, and voluntary students' participation and teachers' involvement. In the process of the learning, some of the challenges faced by the teachers in implementing the approaches are the teaching workloads of both special and general education teachers, scheduling the time table of the inclusive classes, and class control/management of students with diverse levels of understanding/achievement. As a conclusion, coteaching approaches need to be mastered by both special education teachers and general education teachers who are involved in inclusive education. Courses on appropriate teaching approaches and basic special education courses for mainstream teachers are essential in enhancing the teaching efficiency of teachers who are involved in inclusive education.
\end{abstract}

Keywords: Co-teaching approaches, hearing impaired students, mainstream class, special education teacher 


\section{INTRODUCTION}

A learning-friendly environment is very important in an effort to provide a meaningful education for all students, including students with special needs. The World Declaration on Education for All (United Nations 1990) and the Salamanca Statement (UNESCO 1994) uphold the right of every child to receive an education and the opportunity to learn. In the Malaysian Education Development Plan 2013-2025, equal access has also been stated in which every child in Malaysia, regardless of economic status, ethnicity or background, is entitled to equal access to quality education to develop their potential. Inclusive education that provides opportunities for students with special needs to study with general students in the same class is the best way to overcome the problem of discrimination and create a more open learning community in school. However, a study done by Chhabra (2010) found that general education teachers were unprepared and concerned about the students' presence of special needs students in their classrooms. Some of the teachers showed negative attitudes toward inclusive programs and gave many excuses not to accept special needs students in their class due to lack of training and knowledge in special education, large number of students in mainstream classes, limited information on inclusive education, and lack of teaching aids that appropriate in teaching special needs students (Tania 2012). Therefore, to address the issues of having special needs students in the main classroom, collaboration between general education teacher and special education teacher is highly suggested to conduct teaching and learning process in inclusive class. Collaboration, according to Friend \& Cook (2010), is a joint venture based on common goals, equality, shared responsibility to make decisions, joint responsibility for the end result, shared resources, trust in each other, respect and a sense of belonging to the community. Collaboration between special education teachers and general education teachers would benefit the special needs students in the mainstream classroom. Co-teaching approach is a form of collaboration that benefits the inclusive education whereby both teachers, special education and general education need to work together in the teaching and learning process.

\subsection{Co-Teaching Approaches}

Co-teaching is defined as the instructional arrangement in which a general education teacher and a special education teacher deliver core instruction along with specialized instruction, as needed, to a diverse group of students in a single physical space. Co-teaching approaches emphasize on the collaboration and communication between members of a teaching team to meet the learning objectives and learning needs of all students in a classroom. Therefore, co-teaching is typically perceived as two educational professionals working together to teach a group of heterogeneous learners including those with special needs. This teaching partnerships requires educators to make joint instructional decision and share responsibility and accountability for students learning (Shumway et al. 2011)

There are six co-teaching approaches (Figure 1), which are practiced by teachers namely parallel teaching, station teaching, team teaching, alternative teaching, one teach-one observe, and one teach-one assist (Friend \& Cook 2010, Shumway et al. 2011). In parallel teaching, the students are divided into equal-sized groups. Each teacher teaches the same content in the same amount of time and the instructional methods may differ between the groups. The group in this approach does not rotate. Even though, in station teaching, the students are also divided into equal-sized groups and each teacher teaches a portion of the content in the same amount of time but the teachers need to prepare two or more stations in advance for the groups to rotate from one station to another station. Secondary teachers may consider station teaching, especially if they are in block schedules. While team teaching required both teachers to be fully engaged in delivery of the core instruction as both teachers are responsible for classroom management and students' behavior together. On the other hand, in alternative teaching, the teachers need to determine the instructional /intervention needs of class (grouping for the day, who manages specific groups, instructional needs of groups). The teacher who works with the smaller group follows the same lesson plan being implemented by the teacher in the larger group. The small group's instructor makes accommodations and/or modifications to instruction to meet the learning needs of all the students in the classroom. As for one teach and one observe approach, the teachers need to review instructions and mastery of concepts of the subjects taught. The teachers review and record student behaviors for decision making and evaluate the effectiveness and delivery of instructional strategies. Finally, the one teach and one assist approach, the assisting teacher may collect data and observe the learning session to ensure the students understand the lesson taught. The assisting teacher may provide assistance to struggling students and monitor student behavior so that the 
instructing teacher could orchestrate learning tasks and classroom discussion smoothly (Shumway et al. 2012)

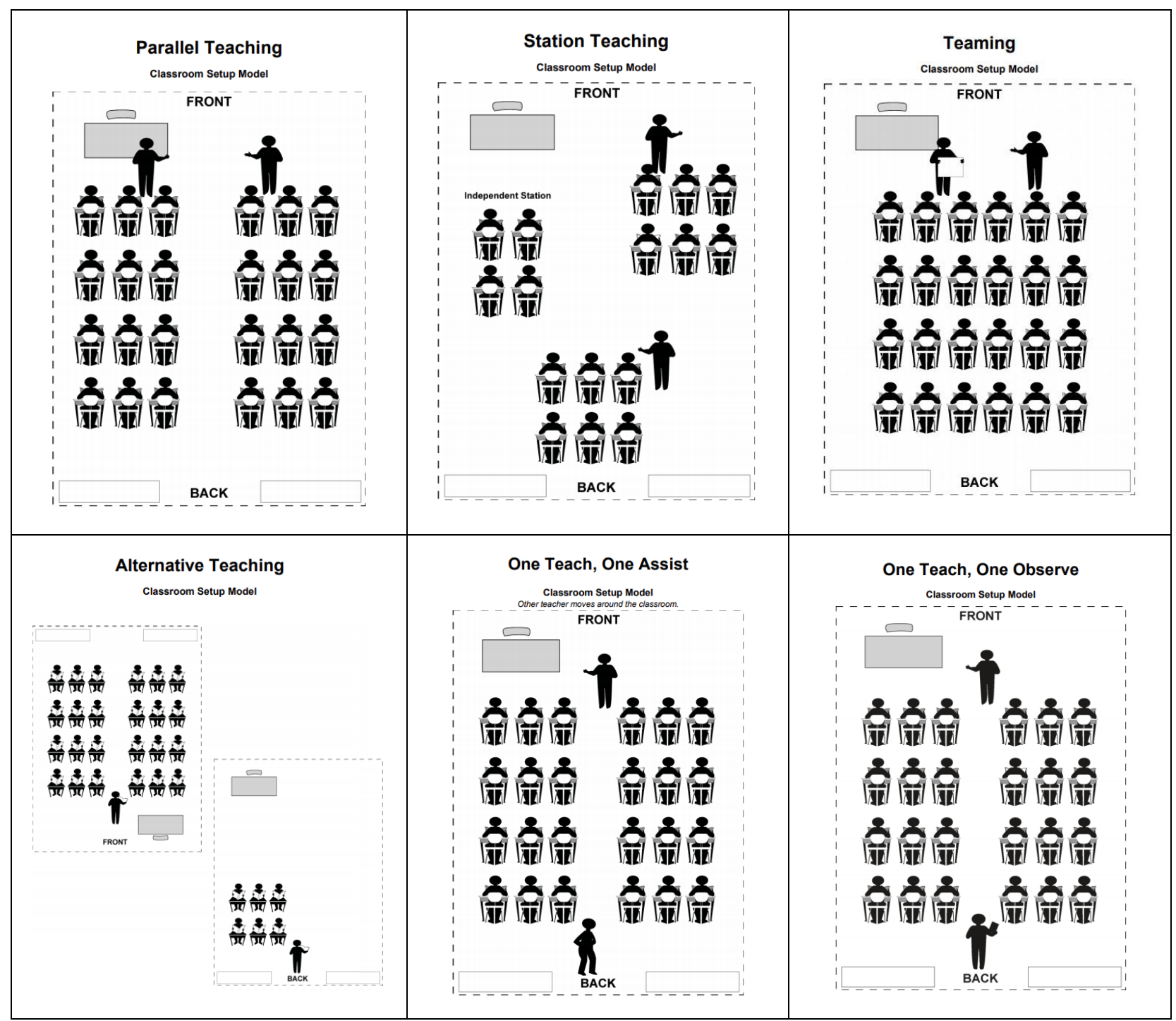

Figure 1: Class layout of co-teaching approaches (Shumway et al. 20141)

Co-teaching approach involves professional planning and delivery of instructions using the six approaches or variations depending on the needs, appropriateness of students and the purpose of the teaching. Gürgür and Uzuner (2010) stated that in the implementation of this teaching model, teachers' perceptions, ways to operate the system, attitudes, opinions and ways of working, influence the success of the program. The concepts of responsibility, honesty, authority, effective communication, sacrifice and mutual respect are understood to create a harmonious relationship between both teachers involved. A good relationship between the two teachers would contribute to build a learning-friendly environment for all the students in the classroom. Theco-teaching approach chosen by the teachers should be agreed with the partner teacher. A research done by Davis and colleagues (2012) reported that teachers frequently used the one teach-one assist approach and team teaching. The findings of the study by Scruggs et al. (2007) found that administrators, teachers and students involved in the co-teaching approach agreed that not only the approach impact the students academically but also their social development. It also have positive impact on the general students and the professional development of teachers. Costella \& Boyle (2013) in their study found that teachers' attitudes towards inclusive became less positive after several years of teaching due to their increased workload. Positive attitudes of the teachers towards inclusive education is important to ensure the successful of teaching in inclusive classes. Leader-Janssen et al. (2012) argued that if teachers could receive assistance and guidance from other involved teachers, it would benefit students as it could use or adapt the mainstream curriculum to suit the learning needs of special needs students in the class. Planning and preparation in collaborative teaching is an important thing to do before teaching and learning is 
carried out. Thus, teachers involved in the implementation of collaborative teaching, whether special education teachers or special teachers must allocate time to do planning and reflection (Gürgür \& Uzuner 2010). However, Brendle et al. (2017) stated that both teachers need further training to understand the models and strategies to implement the co-teaching approach effectively due to lack of expertise and knowledge in special education. According to Stobaugh and Everson (2019), training is greatly needed to assist the teachers to master the teaching approaches that appropriate to students with special needs. Furthermore, Soo Bee Fong \& Zalizan (2010) added that the planning of the learning session and resource preparation are factors that influenced the development of inclusive practices so, teachers need to be sensitive to the actions that must be taken in delivering effective teaching to students with special needs. Factor that contributed to the success of collaborative teaching was the training received by the teachers involved. General education teachers were not ready to teach students with special needs in their mainstream classes. Thus, in the implementation of co-teaching for hearing impaired students, special education teachers and general education teachers need to be trained so that they were knowledgeable about related issues such as inclusive education, support services and cooperative skills. These would enable the involved teachers to do the planning effectively and use resources more successfully to the benefits of the students. Bronson and Dentith (2014) also mentioned that more efforts need to be made to provide training and professional development related to collaboration that may encourage teachers to forge relationships in order to form collaborations in teaching or strengthen existing relationships with partners based on teaching objectives. Support from administrator is important to ensure that the teachers involved in co-teaching could carry out their collaborations successfully. Leader-Janssen et al. (2012) suggested that school administration encourage the general education teachers to get involve and engage in co-teaching with special education teachers. In addition, the school administrators could conduct skills-related training in co-teaching to general education teachers to provide them with basic knowledge needed in inclusive education. Furthermore, the compatibility and mutual understanding between the special education teachers and general education teachers are keys to a successful co-teaching approaches. Scruggs et al. (2007) suggested that teachers who were involved in co-teaching should also build good relationships outside the classroom, so that they could understand and work well together. Leader-Janssen et al. (2012) emphasized open communication in an effort to build good relationships between the two teachers involved and described that the special education teachers play crucial role in ensuring that the needs of students with special needs were met during the learning and teaching process in the mainstream class. Thus, the specials education teachers for hearing impaired students in the mainstream would have to translate the general education teacher speech, voicing the hearing impaired students' student sign language, mediating communication between the hearing impaired students and their hearing peers.

\section{PROBLEM STATEMENT}

The goal of inclusive education is to create academic and social integration for all students including those with special needs. Inclusive education for hearing impaired face a greater challenge as it involves communication. Hearing impaired students showed lack of participation due to difficulties in interaction with their hearing peers and teachers. General education teachers who were involved in inclusive of hearing impaired students did not have sign language skills, which limited their communication during the lesson in class. A study by Musengi et al. (2013) discovered that general teachers who teach hearing impaired students without sign language were found to be less successful compared to teachers who seek the help from specialized personnel in hearing impaired individuals as interpreter to help with the communication in the classroom. Co-teaching is an alternative approach used to teach hearing impaired students in an inclusive classroom. Branson and Dentith (2014) identified that the lack of training for teachers in implementing co-teaching would cause teachers' interest and commitment to decline although this approach is beneficial to the students. Meanwhile, general education teachers were not ready to teach students with special needs due to lack of skills in terms of curriculum modification and individual assessment based on individual lesson plans (Conderman \& Rodriguez 2009). Among the matters that need to be emphasized in teaching hearing impaired students with hearing peers in inclusive classes were related to the development of communication, academic and social. Problems experienced by students with hearing impairment were language proficiency and communication that impacted their self-development. Furthermore, Theunissen et al. (2014) stated that language development and communication skills affect self-esteem in the social domain among peers The hearing impaired students have low self-esteem compared to the hearing friends of the same age. The low self-esteem happens due to their language proficiency and limited communication skills. Therefore, appropriate teaching approaches should be used to help hearing impaired students to overcome the difficulties to communicate and increase self-confidence to participate not only in the inclusive class but also during other learning activities in school. So that they could learn together with hearing peers effectively. 


\section{METHODOLOGY}

This case study was conducted by interviewing three purposely selected special education teachers of a secondary school which provide a Special Education Integration Program for students with hearing impairment. Each of the teachers who were involved in the inclusive class of hearing impaired students only taught a subject in the mainstream class. A teacher who taught Geography has 6 years of teaching experience. While both Teacher B who taught Mathematics and Teacher C who taught Science have been teaching for 7 years. The teachers were asked about their experiences and the challenges in implementing co-teaching approaches in a class that have hearing and hearing impaired students. The results of the interviews were transcribed verbatim and analyzed based on the themes identified in the implementation of co-teaching. Interview questions were adapted from the Collaborative Teaching Model (Friend \& Cook 2010) and Research Report: Collaborative and Co-Teaching Practices and Reflections in a Secondary School Setting (Keller \& Norris 2013).

\section{FINDINGS AND DISCUSSIONS}

All three Special Education teachers were found to be proactive in initiating the implementing of co-teaching approach to provide their special needs students the opportunities to learn together with hearing peers in mainstream class. Based on the analysis of the interviews of three special education teacher, four themes have been identified namely teaching approach, benefits to hearing impaired students, challenges faced by the teachers and factors of successful co-teaching.

\subsection{Teaching Approach}

The implementation of co-teaching was only applied to certain subjects namely Geography (Teacher A), Mathematics (Teacher B), and Science (Teacher C). This study found that all of the teachers preferred and only practiced two of the six teaching approaches which were one teach-one assist and parallel teaching. These two co-teaching approaches were chosen based on the appropriateness and the learning needs of both hearing impaired students and their hearing peers.

\subsubsection{One Teach, One Assist}

This co-teaching approach is the preferred approach not only by the special education teachers but also their general education partners. Teacher A said that the collaboration with the general education teacher was important to discuss and plan on how to implement the approach that benefit to all the students in the class. Both teachers discussed the learning needs not only of the hearing impaired students but also their hearing students in the class. Shumway et al. (2011) explained that in implementing one teach-one assist, one teacher has the role of teaching while the second teacher would move and provide assistance to students who need help during the teaching and learning session. The role of special education teachers in inclusive setting was to ensure that the teaching done by the general education teacher was appropriate and understood by the students with hearing impairment. Furthermore, the special education teachers in the mainstream class were the interpreters in assisting not only the special needs students but also the general teacher and hearing classmates in communicating. The special education teachers assisted in delivering the lesson taught in the class by using sign language to the hearing impaired student. Teacher A also interpreted the sign language from the hearing impaired students to the mainstream teacher and their hearing classmates. Throughout the learning and teaching process, the special education teachers become the moderator of communication between the teachers and students in the classroom. Teacher $\mathrm{C}$ added that she was signing to the students while the general education teacher was teaching in the class. Sometimes Teacher A simplified the lesson so that the hearing impaired student understood what was being taught in the class. In this approach, the hearing impaired students were included in a group with hearing students. Special education teachers also played the role as facilitators and help hearing impaired students to interact during learning activities. General education teachers who have limited skill in sign language would rely on the special education teachers to deliver the teaching content and to communicate with the special needs students. Special education teachers were the interpreters and assistants who monitor the learning and teaching process from one group to another group according to the needs of hearing impaired students in the groups. They also assisted struggling students during the learning process and monitor their behavior while general education teacher teaching at the front of the class (Shumway et al. 2011).

\subsubsection{Parallel teaching}

The second approach that was practiced by the teachers is parallel teaching. Parallel teaching is when both teachers are teaching the same information, but they divide the class into equal group and teach 
simultaneously. This allows for more support, more supervision and greater participation from students during the learning process. Each teacher teaches the same content in the same amount of time but the instructional methods might be different as it was based on the learning needs of the students in the group. Parallel teaching where two teachers teach the same lessons simultaneously to different groups of students. Special education teachers were found to modify the content of the meet the learning needs and levels of understanding of students with special needs. Shumway et al. (2011) explained that during parallel teaching, both teachers would convey the same information; the difference is that students would be divided into two groups and teaching would be done simultaneously. Students would benefit more if they get more attention and opportunities to respond during the teaching and learning process. Special education teachers used sign language in delivering the lesson while general education teachers teaching the other group verbally. In teaching Science in the laboratory, the students were divided in two groups, the first group were at the front of the Lab with general education teacher, while the other group with hearing impaired student at the back with Teacher $\mathrm{C}$. The experiments were conducted separately but simultaneously for both groups. Teacher $\mathrm{C}$ would consult the mainstream teacher, if encountered any difficulties during the lesson/experiment. Teacher $\mathrm{C}$ also would make preparation earlier, so that the lesson would be smoothly taught to the hearing impaired students without forgetting the hearing students in the group. Co-teaching is a collaborative style of delivery that can support the learning of students with special needs as well as typical students who follow the same learning process (Friend \& Cook 2010). During the implementation of parallel teaching, communication between teachers is very important so that the problems that arise could be solved immediately. Hearing students who study together in the group also assist their hearing impared student in carrying out the activities assigned or doing the experiment together.

\subsection{Benefits of Co-Teaching}

A study by Bronson \& Dentith (2014) supported that the collaboration between teachers contributes to efforts in creating a conducive environment for student learning as there is room for teachers to improve teaching and classroom management. In addition, students with special needs, general students as well as both teachers involved in co-teaching gain benefits from co-teaching approaches. All teachers in this study agreed that students with special needs have the opportunity to experience new teaching and learning atmosphere that increase their motivation to focus on the learning process in the classroom. Co-teaching also provided opportunities for students with special needs to use the facilities provided by the school together with their heading peers. Teacher B stated that when the teaching and learning session involves both hearing and hearing impaired students in a classroom, it would indirectly cultivate positive values such as being more aware of the diverse learning needs, respecting and accepting the special needs of their hearing impaired peers. While Teacher $\mathrm{C}$ claimed that the awareness of the importance of sign language among hearing students has increased that they were interested to learn sign language so that they could communicate with their hearing impaired peers. In addition, co-teaching also assisted hearing students to socialize and understand their peers with hearing impairment better as they were willing to learn and use sign language to interact with each other.

Furthermore, these students have been the peer buddies for the hearing impaired students. Teacher A also shared that the hearing students assisted their special needs students in understanding the lesson and did the revision together. Teacher $B$ commented that, at the beginning of the inclusive program, the hearing students were a bit afraid to interact/communicate with their hearing impaired peers but after a few sessions of co-teaching, all the students were more socialized without barriers. Teacher $\mathrm{C}$ also added the collaboration between special education teachers and general education teachers enhanced the special education teachers' knowledge in the subject matters and they were able to teach the subject to special needs students with simplified and different strategies that appropriate to both students learning needs. Teacher A and Teacher B stated that they exchanged views and share knowledge with general education teachers on special education especially deaf education. Teacher $\mathrm{C}$, on the other hand, learnt the teaching strategies in used by general education teachers and applied those strategies when teaching science to hearing impairment students. The interactions that occur during the implementation of co-teaching either to students with special needs or general students, special education teachers or general teachers were a breakthrough in inclusive class. The co-teaching approaches have positive impact on the students' selfesteem and social development of the hearing impaired students.

\subsection{Successful of co-teaching}

The factors that contributed to the successful implementation of co-teaching was the collaboration between special education teachers and general education teachers. Teacher A stated that at the beginning of the program, there were difficulties to start the collaboration, but once they came to an understanding of the 
objectives of the inclusive class, it became easier. Leader-Janssen et al. (2012) said that positive school administration leadership is necessary to determine the success of collaboration in an effort to provide services to students with special needs. Furthermore, Teacher C agreed that the schools' principals and administrators supports on the implementation of co-teaching motivated the teacher to practice co-teaching in inclusive class even though there were no specific guidelines in its implementation. Since there was no provision for conducting co-teaching approaches in inclusive classes, the administration involvement in the program becomes one of the contributing factors to a successful co-teaching implementation. A study by Bronson \& Dentith (2014) found that when paired teaching is implemented, instructional leadership was lacking and reported low teaching success. The effectiveness of paired teaching depends on the compatibility and ability of teachers to collaborate with each other and create classrooms that meet the needs of them and students. Teacher A said discussions were conducted before teaching and learning session to make it easier for them to prepare lesson for the topics to be taught. Teacher A also mentioned that further reading and discussion with general education teachers strengthen the existing knowledge and understanding of the topics to be taught. These actions indirectly motivated special education teachers to enhance their existing knowledge so that its inline with the general teachers' knowledge in the subject matters. According to Davis et al. (2012), co-teaching would only be successful if important aspects such as planning and preparation were considered and applied efficiently. In addition to effective teaching practices the teachers also need to address any learning behavior needs of the all the students in the class. Support from administrator is important to ensure that teachers who were involved in co-teaching were provided the resources needed to make this collaboration teaching a success such as the physical space for co-teaching to be practiced in a classroom, laboratory or even workshops.

The other factor that was important in successful co-teaching was the voluntary participation not only the students but also the general education teachers in the inclusive class program. Teacher A was happy to have a general education teacher who volunteered to be the partner in the co-teaching of inclusive class. The study of Scruggs et al. (2007) showed that if special education teachers pair up with general teachers who were not suitable in implementing co-teaching, the learning environment would be tensed and the outcome of the co-teaching would be unsatisfactory. Teacher $\mathrm{C}$, on the other hand, stated even though there were a few general teachers involved in teaching Science subjects, but a general teacher agreed to be involved in the inclusive class after they could work out the scheduling of time table so that both teachers could be together teaching the class. Not only the timetable for both teachers were adjusted and aligned but also the schedule of the hearing impaired students involved were taken into considerations to ensure they could attend the science class with their hearing peers.

In addition, the compatibility and understanding of both teachers involved in conducting co-teaching are crucial to ensure that the objectives of teaching and learning could be achieved efficiently. Compatibility between the teachers was not only exists on the factor of mutual agreement, but involved the sharing of goals and motivation by playing active roles in teaching, planning and managing student behavior in the class (Scruggs et al. 2007). Nierengarten and Hughes (2010) discussed the consistency in conducting collaboration as a factor that opens space for teachers to grow in choosing teaching strategies that suitable for their students learning needs. This consistency refers to special education teachers collaborating with the same general teacher over a period of time, helping them to better understand each other and being able to improve their teaching style and strategies after reflecting their teaching session together. Understanding between teachers needs to be nurtured to create healthy relationships and ensure effective relationships in implementing co-teaching approach (Friend \& Cook 2010). From the results of the interviews, the factors that contributed to the successful implementation of collaborative teaching are strong support from the administrators, planning and preparation made before conducting the teaching and learning session, voluntary participation of general education teachers, compatibility between special education teachers and general teachers as well as matching scheduling.

\subsection{Challenges}

In the implementing the co-teaching approaches, there were several challenges faced by special education teachers such as the teaching workloads of both special and general education teachers, scheduling the time table of the inclusive classes, and class control/management of the students with diverse levels of understanding/achievement. The teaching workloads of both teachers increased as they needed to allocate time to discuss and plan the lesson for the inclusive class. They also needed to prepare the teaching materials and teaching aids that suitable to the learning needs of all the students in the class. Sometimes, Teacher A said that the discussion had to be postponed or the inclusive class could not be conducted because the teachers were involved in official duties or meetings. Teacher $\mathrm{C}$, on the other hand, pointed out 
that there were times when inclusive class couldn't be held because the special education teacher and the hearing impaired students were involved in co-curricular activities at the district, state or national levels.

Another challenge that faced by the teachers was scheduling the time table for the inclusive class. Teacher $\mathrm{C}$ reported that the time table for mainstream classes was frequently changed and it was a difficult task to align the special classes' time table to the mainstream classes' time table in order for the hearing impaired students to be able to join the mainstream classes. These hearing impaired students were not fully inclusive in the mainstream classes. They only attended a few classes based on certain subjects after their level of achievement on the subjects were assessed and met the criteria to be inclusive in that classes for that particular subjects. Teacher A could only participate in co-teaching in the mainstream class once a week throughout the school term. Teacher A discussed with the general education teacher about the lesson of the week and inquired about the students existing knowledge on the subject as it would be easier to prepare the lesson that involved hearing impaired students. On the other hand, Teacher B collaborated with general Mathematics teacher to co-teach only for drilling the students before tests or examinations were held. General Mathematics teachers would discuss questions by topics and assisted by special education teachers, while students with special needs would be in groups with hearing students. While Teacher $\mathrm{C}$ conducted science experiments in the laboratory with a general Science teacher which allocated two periods of 80 minutes in the laboratory. The scheduling become a challenged because of the limited time allocated for them to use the laboratory and limited number of laboratories in school that available were the problems to co-teach science subject to hearing impaired students. If this happened frequently, it was impossible to co-teaching the science class. According to Bronson \& Dentith (2014), a collective approach that encourages dialogue, reflection and critical thinking sessions in which teachers allocate time to discuss, plan and think about their work as teachers and couples in teaching and learning sessions or in groups is a challenge to implement nowadays as teachers face time constraints and the amount of learning that needs to be delivered; yet, it is important for teachers to realize that their goal is to improve the learning needs of all students in the class.

Among other problems faced by the teachers, was to control/manage the students during the teaching and learning process in the classroom. Teacher $\mathrm{C}$ highlighted the challenges given by the hearing impaired students as they have different hearing impairment. Some of these students also have social, emotional dan behavior issues that sometimes need to be addressed by the teachers during the class session. But according to Teacher B, sometimes the hearing students also misbehaved and caused disruption to the learning process in the class. Apart from that, the hearing impaired students also struggling in using sign language and hence communication in the class was difficult and limited. When compared to hearing peers, the hearing impaired students were more likely to be left in the achieving the learning objectives. However, environmental factors such as socializing with classmates, peers for communication purposes (various interpreters and hearing impaired peers) and different conversation contexts between the other students at school and teachers could assist hearing impaired students in developing their ability to master language (Beal-Alvarez, 2014). These collaboration of communication between the students in the classroom also increased the learning process of students with special needs and awareness to hearing students.

In an inclusive class, the issues of the diverse students' level of understanding/achievement should be the focus of the teaching objectives. With different level of understanding between the hearing and hearing impaired students, the planning of the lesson should be more flexible and accordingly to all the students level of understandings. Nierengarten and Hughes (2010) argued that when collaboration occurs, teachers often overlook the aspect of student placement in the classroom. The tendency to place many at-risk students or students with special needs in the classroom with two teachers should be avoided. The ratio of students with special needs should be commensurate with the number of general students. If there are class problems in terms of student ratio, class reshuffle and rescheduling should be done. Therefore, the teachers involved need to work together in dealing with the problems caused by the students so that the implementation of coteaching could continue smoothly.

\section{CONCLUSION}

The findings of this study have shown that co-teaching approaches chosen by the teachers gave positive impacts not only to the hearing impaired students in learning achievement but also increased the hearing peers' awareness of the learning process with their special needs classmate. In addition, the support from the school administrative personnel also motivated the teachers to conduct co-teaching in the classrooms. Even though co-teaching is chosen to be as an alternative teaching approach that were practiced by the teachers, but they faced challenges such as scheduling the time table for the inclusive classes, the teachers' teaching workloads, the diverse students' level of understanding/achievement and classroom control/ 
management. Most importantly the good rapport and collaboration between the special education teachers and general education teachers that would influence the success of co-teaching as they were involved closely and worked together in planning and preparing the lesson together before the teaching and learning process in the classroom. Therefore, co-teaching approaches need to be mastered by both special education teachers and general teachers involved in the inclusive classes to ensure that the learning objectives are achieved not only for the hearing students but also their hearing impaired peers in the class. As a conclusion, courses on appropriate teaching approaches and basic special education courses for general education teachers are essential in enhancing the teaching efficiency of the teachers who are involved in inclusive education.

\section{ACKNOWLEDGEMENT}

This work was supported by a research fund from Faculty of Education, Universiti Kebangsaan Malaysia. (FPEND GG-2019-029).

\section{REFERENCE LIST}

Brendle, J. Lock, R. \& Piazza, L (2017). A Study of Co-Teaching Identifying Effective Implementation Strategies. International Journal of Special Education.32(3), 538-550.

Bronson, C., E \& Dentith, A., M. (2014). Partner Teaching: A Promising Model. Education 134 (4): $506-520$.

Chhabra, S. (2010). Inclusive Education in Botswana: The Perceptions of Schools Teachers. Journal of Disability Policy Studies 20(4): 219-228.

Conderman, G. \& Rodriguez, S., J. (2009). Beginning teachers' views of their collaborative role. Preventing School Failure 53(4).

Costello, S. \& Boyle, C. (2013). Preservice Secondary Teachers' Attitude Towards Inclusive Education. Australian Journal of Teacher Education. 38(4), 129-143

Davis, K., E., B., Dieker, L., Pearl, C. \& Kirkpatrick R., M. (2012). Planning in the middle: Co-planning between General and Special Education. Journal of Educational and Psychological Consultation 22: 208-226.

Friend, M. Cook, L., Hurley-Chamberlain, D, \& Shamberger, C. T. (2010). Co-Teaching: An illustration of Complexity of Collaboration in Special Education. Journal of Educational and Psychological Consultation 20,9-27

Friend, M., \& Cook, L. (2010). Interactions: Collaboration Skills for School Professionals. Edisi ke-6. Upper Saddle River, NJ: Pearson/Merrill

Beal-Alvarez, J. S. (2014). Deaf Students' Receptive and Expressive American Sign Language Skills: Comparisons and Relations. Journal of Deaf Studies and Deaf Education.

Boyle, C., Scriven, B., Durning, S. \& Downes C. (2011). Facilitating the Learning of All Students: The 'Professional Ppositive' of Inclusive Practice in Australian Primary Schools. Support for Learning 26(2):72-78.

Gürgür, H. \& Uzuner, Y. (2010). A Phenomenological Analysis of the Views on Co-Teaching Applications in the Inclusion Classroom. Educational Sciences: Theory \& Practice 10(1): 311-331.

Keller, L., \& Norris, C. (2013). Research Report: Collaborative and Co-Teaching Practices and Reflections In A Secondary School Setting. Dr. Stirling McDowell Foundation for Research into Teaching Inc.

Leader-Janssen, E., Swain, K., D., Delkamiller, J., \& Ritzman, M., J. (2012). Teachers working with students with disabilities. Journal of Instructional Psychology 39(2).

Musengi, M., Ndofirepi, A. \& Shumba, A. (2013). Rethinking education of deaf children in Zimbabwe: Challenges and opportunities for teacher education. Journal of Deaf Studies and Deaf Education 18 (1).

Nierengarten, G. M., \& Hughes, T. (2010). What Teachers Wish Administrators Knew About Co-Teaching in High Schools, Electronic Journal for Inclusive Education, 2 (6).

Scruggs, T. E., Mastropieri, M. A., \& McDuffie, K. A. (2007). Co-teaching in inclusive classrooms: A 
metasynthesis of qualitative research. Exceptional Children, 73(4), 392-416

Shumway, L. K., Gallo, G., Dickson, S. \& Gibbs, J. (2011). Co-Teaching Handbook: Utah Guidelines. Utah State Office of Education. http://www.schools.utah.gov/sars/DOCS/resources/coteach.aspx

Stobaugh, R. \& Everson, K. (2019). Student Teacher Engagement in Co-Teaching Strategies. Educational Renaissance. 8, 30-47

Soo Bee Fong \& Zalizan Mohd. Jelas. (2010). Amalan program pendidikan inklusif pelajar berkeperluan khas di sebuah sekolah. Fakulti Pendidikan, Universiti Kebangsaan Malaysia

Tania Afreen Khan. (2012). Secondary school teachers' perceptions of inclusive education in Bangladesh. Critical Literacy: Theories and Practices 6(2):102-118

Theunissen, S. C., Rieffe, C., Netten, A. P., Briaire, J. J., Soede, W., Kouwenberg, M., Frijns, J. H. M. (2014) Self-esteem in hearing-impaired children: The influence of communication, education, and audiological characteristics. PLOS ONE. https://doi.org/10.1371/journal.pone.0094521

UNESCO. (1994). The Salamanca Statement and Framework for Action on Special Needs Education. Paris: UNESCO.

Zalizan Mohd Jelas. 2012. Pendidikan Inklusif. DIm. Zalizan Mohd Jelas (peny.). Pendidikan Kanak-Kanak Berkeperluan Khas. Konsep \& Amalan, hlm. 109-138. Bangi: Fakulti Pendidikan, Universiti Kebangsaan Malaysia. 